\title{
Skin Healing of Deep Second Degree Burn Injuries in Four Individuals Sustained in a Boat Explosion-Results after Different Approaches
}

\author{
Vincent März * and Peter M. Vogt \\ Department of Plastic, Aesthetic, Hand and Reconstructive Surgery, Burn Center, \\ Hanover Medical School (MHH), Carl-Neuberg-Straße 1, 30625 Hannover, Germany; \\ vogt.peter@mh-hannover.de \\ * Correspondence: Maerz.Vincent@mh-hannover.de
}

Received: 29 July 2020; Accepted: 14 September 2020; Published: 16 September 2020 updates

\begin{abstract}
Intermediate and deep second-degree skin burn injuries are an ongoing challenge for burn surgeons, with the difficult decision regarding whether to handle them with either conservative or operative methods. In this study, the outcome of similar deep second-degree skin burn injuries is shown with the example of four family members. Clinical outcomes of the four family members which were treated at our burn center in 2017 were analyzed. The areas of burned skin $\left(\mathrm{IIa}^{\circ}-\mathrm{IIb}^{\circ}\right)$ extended from $14 \%$ to $38 \%$ of the total burned skin area. Surgical treatment was adjusted to the rate of epithelialization after the first debridement. The excellent cosmetic long-term results of this patient cohort support the importance of stage-related therapy of deep dermal burn injuries. An initial debridement followed by early coverage is the key to early reconstitution of the epidermal barrier. However, with regard to the late effects of skin substitutes, more sensory alterations, dysesthesia, hyperpigmentation and unstable skin areas are still visible after coverage with glycerol conserved skin. The best results were seen after the use of autologous STGS and synthetic skin.
\end{abstract}

Keywords: burn injury; skin grafts; synthetic skin; allogeneic skin; skin substitutes

\section{Introduction}

Intermediate and deep second-degree skin burn injuries are a challenge for burn surgeons, with the difficult decision as to whether had to handle them with either conservative or operative methods. Options range from stimulated spontaneous healing up to aggressive surgical debridement and grafting. In this naturally occurring randomized prospective study, the outcome of similar deep second-degree skin burn injuries is shown in the example of four family members. All of them (father $50 \mathrm{yrs}$, mother $39 \mathrm{yrs}$, boy $11 \mathrm{yrs}$ and girl $8 \mathrm{yrs}$ ) were exposed to the flames of an exploding boat engine in summer 2017 and demonstrated homogenous patterns of burn injuries. The initial resuscitation took place in two nearby burn centers. Here, all wounds were covered with sterile non adherent dressings. After three days, the girl, the boy and the mother were relocated by plane to our burn center at the Medical School Hannover. One day later, the father followed for further treatments.

\section{Materials and Methods}

Analysis of the treatment of the four family members who were treated at our burn center in 2017 included operation reports, photo documentation and clinical findings up to two years after accident. Follow-ups took place at 6 weeks, 6 months, 12 months and 24 months after trauma. The various second-degree burn injuries $\left(\mathrm{IIa}^{\circ}-\mathrm{IIb}^{\circ}\right.$ ) extended from $14 \%$ to $38 \%$ of total body surface area (TBSA). To assess the TBSA of the patients, we used the Wallace Rules of Nine [1]. 
Conservative and aggressive operative methods were adjusted to the rate of epithelialization after the first debridement on day four and five (Figure 1). The hospital stays ranged from 24 to 38 days. Daily changes of the wound dressings were performed in all patients. As the standard procedure at our burn center, an aseptic washing-lotion (Octenisan ${ }^{\circledR}$ Co., Schülke \& Mayr GmbH, Norderstedt, Germany) and a disinfectant (Octenisept ${ }^{\circledR}$ Co., Schülke \& Mayr GmbH, Norderstedt, Germany) were used for the initial aseptic and hydrotherapeutic debridement. All burn injuries were covered with a hydrogel (Lavanid ${ }^{\circledR}$ wound gel Co., Serag-Wiessner GmbH \& Co. KG, Naila, Germany) and fatty gauze (Jelonet ${ }^{\circledR}$ Co., SMITH \& NEPHEW, Watford, UK). Further treatments were adjusted to the depth of burns and the rate of epithelialization. After superficial and tangential debridement, areas with good bleeding were covered with glycerol conserved allogeneic skin.

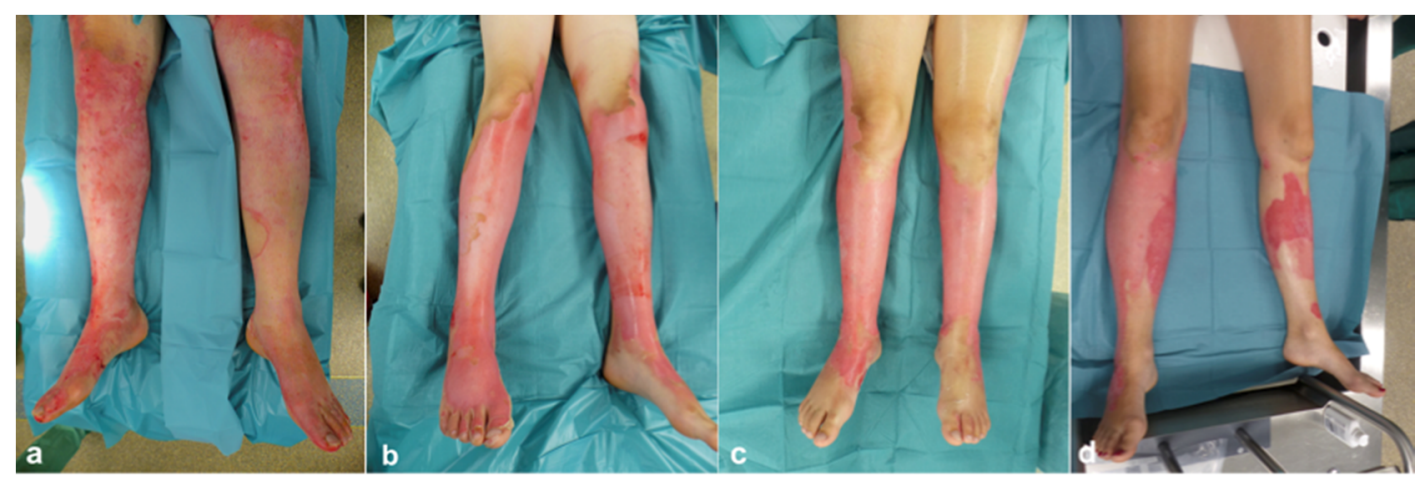

Figure 1. Second degree burn injury after hydrotherapeutic debridement on the lower extremity at initial treatment at burn center. (a): legs of the father, after an aseptic and hydrotherapeutic debridement. (b): legs of the boy, after an aseptic and hydrotherapeutic debridement. (c): legs of the girl, after an aseptic and hydrotherapeutic debridement. (d): legs of the mother, after an aseptic and hydrotherapeutic debridement.

\section{Results}

No infections were observed. Initially the girl showed an intermediate pattern of a deep second-degree skin burn injury with $18 \%$ of TBSA. Burned areas were detected on the dorsal thigh and circular on the lower legs. After the first debridement in general anesthesia, the wounds were covered by polyhexanide (Lavanid ${ }^{\circledR}$ wound gel) and fatty gauze. Four days later, the poorly healing areas were secondly grafted by meshed (1:1.5) thin $(0.2-0.8 \mathrm{~mm})$ allogeneic donor skin (Co. ETB-BISLIFE, Beverwijk, The Netherlands). After seven days, the dry allogeneic skin was removed. Grafted areas showed a good epithelialization. No further operative treatment was necessary. Two years after surgery, in only $8 \%$ of the treated skin some hyperpigmented hot spots with altered skin consistency were detected.

The boy also showed an intermediate pattern of a second-degree skin burn injury with $20 \%$ of TBSA at the right elbow, both lower legs and the left thigh. Burned areas of the boy (20\% TBSA) were directly covered with temporary synthetic skin (Suprathel ${ }^{\circledR}$ PolyMedics, Denkendorf, Germany) after debridement. No further surgical interventions were necessary. All areas regenerated very well with moderate hyperpigmentation.

The mother showed $14 \%$ burned skin of the TBSA in both lower legs and the right elbow. All wounds were directly covered by meshed allogeneic skin grafts $\left(1.170 \mathrm{~cm}^{2}\right)$. With an ongoing epithelialization, allogenic skin was removed step by step. Today, moderate hyperpigmentation and some instability of the epidermis in small areas are still visible. Two years after surgical treatment, residual sensory alterations and dysesthesia remain. 
The wounds of the father on the face, both arms and both legs with $38 \%$ of TBSA were initially treated with hydrogel and fatty gauze. A day later, deep dermal burns on the arms and legs were covered by meshed allogeneic glycerol conserved skin grafts $\left(4.540 \mathrm{~cm}^{2}\right)$. One week later, the allogenic skin on both lower legs was removed and the moderately epithelialized areas were treated with sprayed cell suspension (ReCell ${ }^{\circledR}$ Avita Medical, Cambridge, UK). Both arms were covered with temporary synthetic skin (Suprathel ${ }^{\circledR}$ PolyMedics) after the removal of the allogeneic skin.

Three weeks after the accident, non-healing areas on the lower left leg and foot were debrided and definitely covered by autologous skin grafts. Today, hyperpigmentation and some unstable areas, edema and scars in the lower legs persist.

All wounds healed within four weeks. Early results after 6 weeks postoperatively are shown in Figure 1, and after 6 months in Figure 2. Long term results 12 months and 24 months after trauma are presented in Figures 3 and 4, respectively.

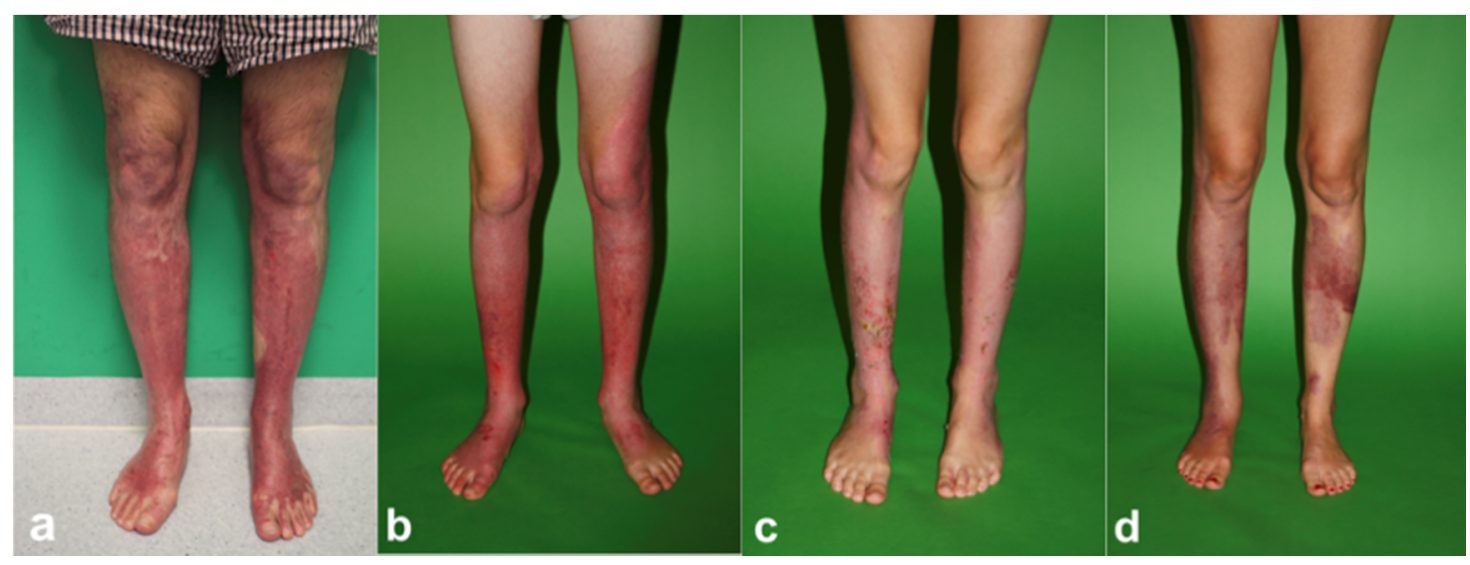

Figure 2. Results after 4-6 weeks after conservative and aggressive operative treatment of second-degree burn injury on the lower extremity. (a) Legs of the father, after treatment with allogeneic glycerol conserved skin grafts and keratinocyte suspension $\left(\operatorname{ReCell}{ }^{\circledR}\right)$. (b) Legs of the boy, after treatment with temporary synthetic skin (Suprathel ${ }^{\circledR}$ ). (c) Legs of the girl, after allogeneic skin transplantation. (d) Legs of the mother, after the removal of meshed allogeneic skin grafts.

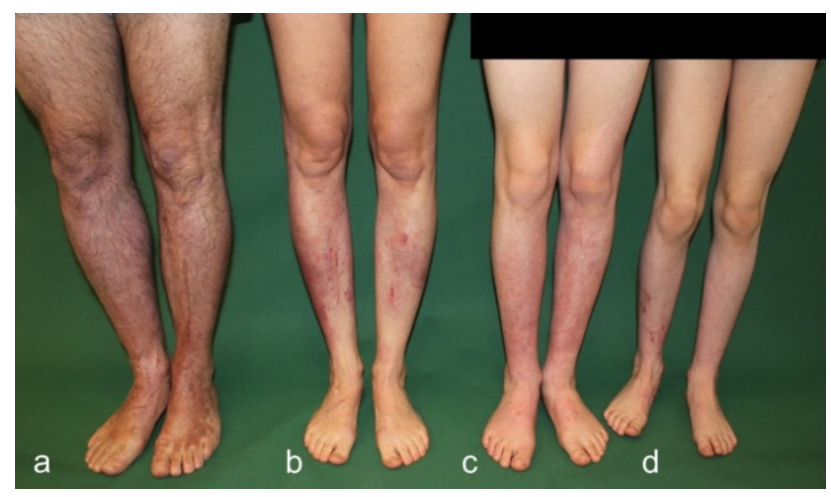

Figure 3. Results 12 months after conservative and aggressive operative treatment of second-degree burn injury on the lower extremity. (a) Legs of the father, after treatment with allogeneic glycerol conserved skin grafts and keratinocyte suspension $\left(\operatorname{ReCell}{ }^{\circledR}\right)$. (b) Legs of the mother, after the removal of meshed allogeneic skin grafts. (c) Legs of the boy, after treatment with temporary synthetic skin (Suprathel ${ }^{\circledR}$ ). (d) Legs of the girl, after allogeneic skin transplantation. 


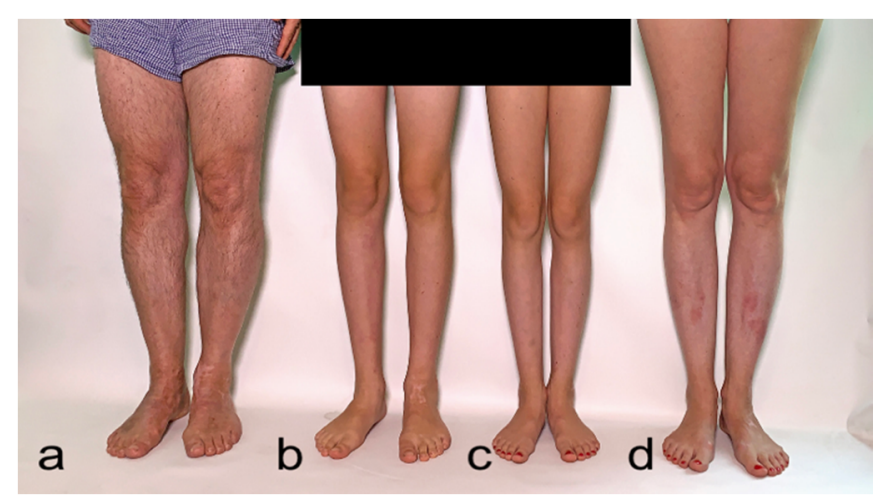

Figure 4. Results 24 months after conservative and aggressive operative treatment of second-degree burn injury on the lower extremity. (a) Legs of the father, after treatment with allogeneic glycerol conserved skin grafts and keratinocyte suspension $\left(\operatorname{ReCell}{ }^{\circledR}\right)$. (b) Legs of the boy, after treatment with temporary synthetic skin (Suprathel ${ }^{\circledR}$ ). (c) Legs of the girl, after allogeneic skin transplantation. (d): Legs of the mother, after the removal of meshed allogeneic skin grafts.

\section{Discussion}

The excellent functional and cosmetic long-term results of this patient cohort suffering from the same accident and identical exposure to the explosive mechanism support the efficacy of a stage-related therapy of deep dermal burn injury. The early initial debridement followed by early coverage is the key to early reconstitution of the epidermal barrier [2]. For deep second-degree burn injury, the stimulation of epithelialization with temporary synthetic skin, temporary allogeneic skin grafts and the final treatment with split thickness skin grafts (STGS) or a cell suspension is the best option for excellent clinical and aesthetic results.

The main advantage of the use of Suprathel ${ }^{\circledR}$ is the reduction in pain along with the absence of any donor site morbity. Additionally, fewer dressing changes in comparison to the conservative use of hydrogel and fatty gauze are necessary [3]. The key for a good adherence of synthetic temporary membranes (Suprathe $l^{\circledR}$ ) on the wound bed and an early reepithelialization within 10 to 21 days without any infection is a proper initial superficial wound debridement $[4,5]$.

Keratinocyte suspension $\left(\mathrm{ReCell}^{\circledR}\right)$ provides excellent aesthetic results with early epithelialization and a good skin quality [6]. The main advantage of ReCell ${ }^{\circledR}$ is the rather small donor site, so an expansion ratio of 1:80 is still possible [7,8]. Since March 2019, ReCell ${ }^{\circledR}$ is no longer available in the EU because of administrative and procedural non-conformities in EU certificates.

The use of meshed allogeneic glycerol conserved skin grafts is also very comfortable for the patients with the absence of any donor site morbity and the reduction in pain. The results show a very good reepithelialization and often no further operative treatment was necessary. The use of allogenic skin in deep dermal burn injury with a TBSA more than $10 \%$ should be considered.

With autologous split-thickness skin grafts, the early coverage of the burned areas with immediately stressable skin is still possible. Mechanically stressed body areas such as finger joints can also be treated well [7]. Disadvantages include the painful and large donor areas and the often unsightly patterns of the skin. However, STGS are the gold standard in the treatment of burn skin injury because an early restoration of the epidermal barrier with pliable dermis provides very good aesthetic and functional results [6].

With regard to the late effects of the use of allogeneic and autologous skin grafts, more sensory alterations, dysesthesia, hyperpigmentation and unstable skin areas are still visible, in particular after coverage with glycerol conserved skin. The best results were seen after the use of STGS and synthetic skin. 


\section{Conclusions}

In more than $90 \%$ of patients, the burned body area is less than $10 \%$ of TSBA. Therefore, besides the functional aspects, aesthetic considerations have become more and more important. Therefore, STGS, synthetic skin or the use of a cell suspension with a small donor site are good options for the treatment of burn injuries with intermediate and deep second-degree skin burn injuries.

Author Contributions: V.M. and P.M.V. designed and wrote the manuscript. All authors have read and agreed to the published version of the manuscript.

Funding: This research received no external funding.

Acknowledgments: In this section you can acknowledge any support given which is not covered by the author contribution or funding sections. This may include administrative and technical support, or donations in kind (e.g., materials used for experiments).

Conflicts of Interest: The authors declare no conflict of interest.

Ethical Approval: This is a case report in which no research has been done. The name of the patients is not disclosed. Ethical approval was not required. Patients have given consent to publish the photographs in scientific publications.

\section{References}

1. Moore, R.A.; Waheed, A.; Burns, B. Rule of Nines. In StatPearls; StatPearls Publishing: Treasure Island, FL, USA, 2020.

2. Wood, F.; Lewis, D.; Martin, L.; McWilliams, T.; Burrows, S.; Rea, S.; Rawlins, J. A prospective randomised clinical pilot study to compare the effectiveness of Biobrane ${ }^{\circledR}$ synthetic wound dressing, with or without autologous cell suspension, to the local standard treatment regimen in paediatric scald injuries. Burns 2012, 36, 830-839. [CrossRef]

3. Schwarze, H.; Küntscher, M.; Uhlig, C.; Hierlemann, H.; Prantl, L.; Ottomann, C.; Hartmann, B. Suprathel, a new skin substitute, in the management of partial-thickness burn wounds: Results of a clinical study. Ann. Plast. Surg. 2008, 60, 181-185. [CrossRef]

4. Rashaan, Z.M.; Krijnen, P.; Allema, J.H.; Vloemans, A.F.; Schipper, I.B.; Breederveld, R.S. Usability and effectiveness of Suprathel ${ }^{\circledR}$ in partial thickness burns in children. Eur. J. Trauma Emerg. Surg. 2017, 43, 549-556. [CrossRef]

5. Hundeshagen, G.; Collins, V.N.; Wurzer, P.; Sherman, W.; Voigt, C.D.; Cambiaso-Daniel, J.; Nunez Lopez, O.; Sheaffer, J.; Herndon, D.N.; Finnerty, C.C.; et al. A Prospective, Randomized, Controlled Trial Comparing the Outpatient Treatment of Pediatric and Adult Partial-Thickness Burns with Suprathel or Mepilex Ag. J. Burn Care Res. Off. Publ. Am. Burn Assoc. 2018, 39, 261-267. [CrossRef] [PubMed]

6. Gravante, G.; Di Fede, M.C.; Grimaldi, M.; De Angelis, B.; Arpino, A.; Cervelli, V.; Montone, A. A randomized trial comparing ReCell system of epidermal cells delivery versus classic skin grafts for the treatment of deep partial thickness burns. Burns J. Int. Soc. Burn Inj. 2007, 33, 966-972. [CrossRef] [PubMed]

7. Holmes IV, J.H.; Molnar, J.A.; Carter, J.E.; Hwang, J.; Cairns, B.A.; King, B.T.; Smith, D.J.; Cruse, C.W.; Foster, K.N.; Mozingo, D.W.; et al. A Comparative Study of the ReCell ${ }^{\circledR}$ Device and Autologous Split-Thickness Meshed Skin Graft in the Treatment of Acute Burn Injuries. J. Burn Care Res. Off. Publ. Am. Burn Assoc. 2018, 39, 694-702. [CrossRef] [PubMed]

8. Hu, Z.-C.; Chen, D.; Guo, D.; Liang, Y.Y.; Zhang, J.; Zhu, J.Y.; Tang, B. Randomized clinical trial of autologous skin cell suspension combined with skin grafting for chronic wounds. Br. J. Surg. 2015, 102, e117-e123. [CrossRef] [PubMed] 